\title{
Effect of acetazolamide on stable carbon isotope fractionation in Chlamydomonas reinhardtii and Chlorella vulgaris
}

\author{
WU YanYou ${ }^{1 *}$, XU Ying ${ }^{1,2}$, LI HaiTao $^{1,2} \&$ XING DeKe ${ }^{1,2}$ \\ ${ }^{1}$ State Key Laboratory of Environmental Geochemistry, Institute of Geochemistry, Chinese Academy of Sciences, Guiyang 550002, China; \\ ${ }^{2}$ Graduate University of Chinese Academy of Sciences, Beijing 100049, China
}

Received June 22, 2011; accepted September 22, 2011; published online November 26, 2011

\begin{abstract}
The effect of extracellular carbonic anhydrase (CAex) on stable carbon isotope fractionation in algae is still unclear. The stable carbon isotope composition and algal growth in the presence and absence of the membrane-impermeable CA inhibitor acetazolamide were compared in Chlamydomonas reinhardtii and Chlorella vulgaris. The CAex of both algal species contributed about $9 \%$ of the stable carbon isotope fractionation and exhibited a dosage effect. Therefore, evidence in vivo that CAex leads to a larger carbon isotope fractionation of algae is presented.
\end{abstract}

acetazolamide, algae, bicarbonate, carbonic anhydrase, stable carbon isotope

Citation: $\quad$ Wu Y Y, Xu Y, Li H T, et al. Effect of acetazolamide on stable carbon isotope fractionation in Chlamydomonas reinhardtii and Chlorella vulgaris. Chin Sci Bull, 2012, 57: 786-789, doi: 10.1007/s11434-011-4861-9

The isotopic composition of sedimented algal material is an indicator of paleoenvironmental conditions because of the well-documented effect of $\mathrm{CO}_{2}$ concentration on marine algal carbon fractionation [1-3]. However, use of existing models for prediction of algal carbon isotope fractionation revealed a large deviation in some aquatic ecosystems [4]. This deviation, if not considered in prediction models, would affect the precision of predictions of paleoenvironmental $\mathrm{CO}_{2}$ concentrations based on the carbon isotope composition.

The deviation from the model-predicted isotope fractionation results not only from environmental factors, but also from some important physiological factors. Extracellular carbonic anhydrase action might be one of the main physiological processes that lead to the deviation. Carbonic anhydrase (CA; EC 4.2.1.1), a zinc-containing metalloenzyme, catalyzes the reversible interconversion between bicarbonate $\left(\mathrm{HCO}_{3}^{-}\right)$and $\mathrm{CO}_{2}$. The uncatalyzed, slow interconversion between $\mathrm{CO}_{2}$ and $\mathrm{HCO}_{3}^{-}$produced about $10 \%$ of the stable carbon isotope fractionation, whereas the intercon-

*Corresponding author (email: wuyanyou@mails.gyig.ac.cn) version in vitro catalyzed by CA had only $1.1 \%$ fractionation $[5,6]$.

The present study examines the effects of extracellular CA (CAex) on carbon isotope fractionation by comparison of the stable carbon isotope composition and algal growth with and without the membrane-impermeable CA inhibitor acetazolamide (AZ) in Chlamydomonas reinhardtii and Chlorella vulgaris. Evidence in vivo showed that extracellular CA leads to higher algal carbon isotope fractionation.

\section{Materials and methods}

Chlamydomonas reinhardtii and Chlorella vulgaris samples were obtained from the Institute of Hydrobiology, Chinese Academy of Sciences. Both species were grown axenically in artificial freshwater soil extract (SE) medium. Cultures were incubated at $25.0 \pm 1.0^{\circ} \mathrm{C}$ under $150 \mu \mathrm{mol} \mathrm{m}^{-2} \mathrm{~s}^{-1}$ light intensity and a $16 / 8 \mathrm{~h}$ day/night cycle. Experiments were conducted with the following treatments.

Treatment 1: C. reinhardtii and C. vulgaris were grown in SE media that contained different $\mathrm{NaHCO}_{3}$ concentra- 
tions $\left(0,0.5,2,8,16\right.$, or $\left.20 \mathrm{mmol} \mathrm{L}^{-1}\right)$ with or without $\mathrm{AZ}$ $\left(10 \mathrm{mmol} \mathrm{L}^{-1}\right)$. The cultures were treated for $12 \mathrm{~d}$, with the first $8 \mathrm{~d}$ for expanding the culture, and the last $4 \mathrm{~d}$ for strengthening the culture. The added $\mathrm{NaHCO}_{3}$, which has a $\delta^{13} \mathrm{C}$ value of $-17.4 \%$ in solid state, and $-16.6 \%$ in solution, was a tracer for the dissolved inorganic carbon (DIC) sources used by algae.

Treatment 2: C. reinhardtii and $C$. vulgaris were grown in SE media with different $\mathrm{AZ}$ concentrations $(0,0.01,0.10$, 0.50 , or $1.00 \mathrm{mmol} \mathrm{L}^{-1}$ ) and $0.5 \mathrm{mmol} \mathrm{L}^{-1}$ added $\mathrm{NaHCO}_{3}$. The cultures were treated for $14 \mathrm{~d}$, with the first $10 \mathrm{~d}$ for expanding the culture, and the last $4 \mathrm{~d}$ for strengthening the culture. The added $\mathrm{NaHCO}_{3}$ was the same $\delta^{13} \mathrm{C}$ value as that of Treatment 1 .

All experimental treatments consisted of five replicates. Algal proteins were assayed using Coomassie brilliant blue. Aquamerck was used in the titration of bicarbonate concentrations in the media.

The algal cultures were dried prior to analysis and were converted to $\mathrm{CO}_{2}$ at $800^{\circ} \mathrm{C}$ in a quartz tube over copper oxide in an oxygen atmosphere. Water and oxygen were removed from the gas stream in a liquid $\mathrm{N}_{2}$ trap, and $\mathrm{CO}_{2}$ was double distilled and collected into a sample tube. The $\mathrm{CO}_{2}$ sample was analyzed with an isotope ratio mass spectrome- ter (Finnigan MAT 252, Bremen, Germany). All isotopic compositions $\left(\delta^{13} \mathrm{C}\right)$ are expressed as per mille $(\% o)$ and compared with a standard (Pee Dee Belemnite) (see Formula (1)). The analytical precision was $\pm 0.1 \%$.

$$
\delta^{13} \mathrm{C}(\% o)=\left[\left(R_{\text {sample }} / R_{\text {standard }}\right)-1\right] \times 1000,
$$

where $R_{\text {sample }}$ and $R_{\text {standard }}$ are the ratio of heavy to light isotopes $\left({ }^{13} \mathrm{C} /{ }^{12} \mathrm{C}\right)$ of the sample and the standard, respectively.

\section{Results and discussion}

\subsection{Stable carbon isotope composition with and without acetazolamide}

The $\mathrm{CO}_{2}$ and generated $\mathrm{HCO}_{3}^{-}$concentrations varied with the amount of added $\mathrm{HCO}_{3}^{-}$. The total DIC content increased with increasing added $\mathrm{HCO}_{3}^{-}$concentration (Table 1). The $\delta^{13} \mathrm{C}_{\text {DIC }}$ and the proportion of $\mathrm{HCO}_{3}^{-}$obtained from conversion of $\mathrm{CO}_{2}$ to total DIC were high at low added $\mathrm{HCO}_{3}^{-}$ concentrations $\left(0-2.00 \mathrm{mmol} \mathrm{L}^{-1}\right)$, and low at high added $\mathrm{HCO}_{3}^{-}$concentrations $\left(8.00-20.00 \mathrm{mmol} \mathrm{L}^{-1}\right.$ ) regardless of the presence or absence of AZ (Table 1). The $\mathrm{pH}$ in the presence of $\mathrm{AZ}$ was lower than that without AZ. Therefore, the $\mathrm{CO}_{2}$ concentrations in the culture media that contained

Table 1 Concentration of dissolved inorganic carbon and $\delta^{13} \mathrm{C}_{\mathrm{DIC}}$ in original culture media of C. reinhardtii and C. vulgaris

\begin{tabular}{|c|c|c|c|c|c|c|c|}
\hline Treatment & $\mathrm{pH}$ & {$\left[\mathrm{HCO}_{3}^{-}\right]^{\mathrm{a})}\left(\mathrm{mmol} \mathrm{L}^{-1}\right)$} & {$\left[\mathrm{HCO}_{3}^{-}\right]^{\mathrm{b})}\left(\mathrm{mmol} \mathrm{L}^{-1}\right)$} & {$\left[\mathrm{HCO}_{3}^{-}\right]^{\mathrm{c}}\left(\mathrm{mmol} \mathrm{L}^{-1}\right)$} & {$\left[\mathrm{CO}_{2}\right]^{\mathrm{d})}\left(\mathrm{mmol} \mathrm{L}^{-1}\right)$} & Total DIC $\left(\mathrm{mmol} \mathrm{L}^{-1}\right) \delta^{13}$ & $\overline{C_{\text {DIC }}(\%, \text { PDB })}$ \\
\hline \multirow{5}{*}{$\begin{array}{l}\text { Chlamydomonas } \\
\text { reinhardtii } \\
\text {-AZ }\end{array}$} & 6.50 & 0 & 0.80 & 0.80 & 0.61 & 1.41 & -11.8 \\
\hline & 6.87 & 0.50 & 1.60 & 1.10 & 0.52 & 2.12 & -13.7 \\
\hline & 8.54 & 8.00 & 8.20 & 0.20 & 0.06 & 8.26 & -15.9 \\
\hline & 8.82 & 16.00 & 15.70 & -0.30 & 0.06 & 15.76 & -16.5 \\
\hline & 8.88 & 20.00 & 19.40 & -0.60 & 0.06 & 19.46 & -16.6 \\
\hline \multirow{6}{*}{$\begin{array}{c}\text { Chlorella vulgaris } \\
-\mathrm{AZ}\end{array}$} & 6.50 & 0 & 0.80 & 0.80 & 0.61 & 1.41 & -11.8 \\
\hline & 6.87 & 0.50 & 1.45 & 0.95 & 0.47 & 1.92 & -13.5 \\
\hline & 7.75 & 2.00 & 2.70 & 0.70 & 0.11 & 2.81 & -15.6 \\
\hline & 8.54 & 8.00 & 8.20 & 0.20 & 0.06 & 8.26 & -16.5 \\
\hline & 8.82 & 16.00 & 15.45 & -0.55 & 0.06 & 15.51 & -16.6 \\
\hline & 8.88 & 20.00 & 19.5 & -0.50 & 0.06 & 19.56 & -16.6 \\
\hline \multirow{5}{*}{$\begin{array}{l}\text { Chlamydomonas } \\
\text { reinhardtii } \\
+\mathrm{AZ}\end{array}$} & 6.40 & 0.50 & 1.80 & 1.30 & 1.72 & 3.52 & -11.9 \\
\hline & 7.00 & 2.00 & 2.90 & 0.90 & 0.70 & 3.60 & -14.5 \\
\hline & 7.62 & 8.00 & 8.40 & 0.40 & 0.48 & 8.88 & -16.1 \\
\hline & 7.90 & 16.00 & 15.90 & -0.10 & 0.48 & 16.38 & -16.4 \\
\hline & 8.00 & 20.00 & 19.50 & -0.50 & 0.47 & 19.97 & -16.5 \\
\hline \multirow{6}{*}{$\begin{array}{l}\text { Chlorella vulgaris } \\
+\mathrm{AZ}\end{array}$} & 6.00 & 0 & 0.80 & 0.80 & 1.92 & 2.72 & -10.5 \\
\hline & 6.40 & 0.50 & 1.60 & 1.10 & 1.53 & 3.13 & -12.0 \\
\hline & 7.00 & 2.00 & 2.80 & 0.80 & 0.67 & 3.47 & -14.5 \\
\hline & 7.62 & 8.00 & 8.25 & 0.25 & 0.47 & 8.72 & -16.1 \\
\hline & 7.90 & 16.00 & 15.70 & -0.30 & 0.47 & 16.17 & -16.4 \\
\hline & 8.00 & 20.00 & 19.50 & -0.50 & 0.47 & 19.97 & -16.5 \\
\hline
\end{tabular}

a) $\mathrm{NaHCO}_{3}$ concentration added to the culture medium; b) $\mathrm{NaHCO}_{3}$ concentration in the culture medium; c) $\mathrm{HCO}_{3}^{-}$concentration from the conversion of $\left.\mathrm{CO}_{2} ; \mathrm{d}\right)$ concentration of $\mathrm{CO}_{2}$ in the medium. 
AZ were higher than in the media lacking AZ.

The stable carbon isotope composition and growth of $C$. reinhardtii and $C$. vulgaris varied with the total DIC with and without $\mathrm{AZ}$ (Figure 1). Protein content increased at low added $\mathrm{HCO}_{3}^{-}$concentrations and decreased at high added $\mathrm{HCO}_{3}^{-}$concentrations without AZ. However, in the presence of $\mathrm{AZ}$, the protein content increased independent of $\mathrm{HCO}_{3}^{-}$ concentration.

The stable carbon isotope composition without $\mathrm{AZ}$ was significantly different from that with AZ. The mean $\delta^{13} \mathrm{C}$ values of $C$. reinhardtii and $C$. vulgaris without $\mathrm{AZ}$ were about $9.1 \%$ and $11.4 \%$ more positively skewed than that with $\mathrm{AZ}$ at low added $\mathrm{HCO}_{3}^{-}$concentrations (0-2.00 mmol $\left.\mathrm{L}^{-1}\right)$, respectively. The $\delta^{13} \mathrm{C}$ values of the two algal species were similar (about $-25.5 \%$ ) at 8.00 mmol L ${ }^{-1}$ added $\mathrm{HCO}_{3}^{-}$ regardless of the presence or absence of $\mathrm{AZ}$. The $\delta^{13} \mathrm{C}$ values of $C$. reinhardtii and $C$. vulgaris without $\mathrm{AZ}$ were more negatively skewed than that with $\mathrm{AZ}$ (16.00 and 20.00 mmol $\mathrm{L}^{-1}$ added $\mathrm{HCO}_{3}^{-}$, respectively).

The stable carbon isotope composition in algae reflects the utilization of DIC [7]. Without AZ, the algal cells mainly utilized the $\mathrm{HCO}_{3}^{-}$generated from the rapid interconversion of $\mathrm{CO}_{2}$ catalyzed by $\mathrm{CAex}$ at low added $\mathrm{HCO}_{3}^{-}$ concentrations $\left(0-2.00 \mathrm{mmol} \mathrm{L}^{-1}\right)$. The carbon isotope fractionation was very low (about 1.1\%o) [6]. However, in the presence of $\mathrm{AZ}$, the algal cells mainly used the $\mathrm{HCO}_{3}^{-}$generated from the slow (uncatalyzed) interconversion of $\mathrm{CO}_{2}$ at low added $\mathrm{HCO}_{3}^{-}$concentrations. The slow interconversion between $\mathrm{CO}_{2}$ and $\mathrm{HCO}_{3}^{-}$produced about $10 \%$ of the stable carbon isotope fractionation [5]. Therefore, $\delta^{13} \mathrm{C}$ val- ues in the presence of $\mathrm{AZ}$ at low added $\mathrm{HCO}_{3}^{-}$concentrations were about $9 \%$ less than those in the absence of $\mathrm{AZ}$, regardless of algal growth rate or cell size [8].

Algal growth rate and cell size may affect isotope fractionation [8]. The $\delta^{13} \mathrm{C}$ value is inversely correlated with algal growth rate or cell size [8]. The difference in the $\delta^{13} \mathrm{C}$ values of $C$. reinhardtii with and without $\mathrm{AZ}$ was approximately $9 \%$. This value could be regarded the absolute contribution of CAex. However, greater differences in the $\delta^{13} \mathrm{C}$ values than $9 \%$ o (mean $11.4 \%$ ) were observed in $C$. vulgaris. A small, additional difference (mean 2.4\%o) in the $\delta^{13} \mathrm{C}$ values was recorded in $C$. vulgaris above that produced by CAex. The additional difference might reflect the lower algal growth rate and smaller cell size when $C$. vulgaris was cultured in media that contained AZ.

A linear or stoichiometric relationship existed between the $\delta^{13} \mathrm{C}$ values in the algal cells and the total DIC in culture media lacking $\mathrm{AZ}$ at low added $\mathrm{HCO}_{3}^{-}$concentrations. In natural water bodies, the concentration of $\mathrm{HCO}_{3}^{-}$is much lower than $2.0 \mathrm{mmol} \mathrm{L}^{-1}$ [9]. Thus, we also deduced that the difference in carbon isotopic fractionation is large between algae with high CAex activity and that without CAex activity.

The $\delta^{13} \mathrm{C}$ value of added $\mathrm{HCO}_{3}^{-}$was more negative than that of the control $\left(0 \mathrm{mmol} \mathrm{L}{ }^{-1}\right.$ added $\left.\mathrm{HCO}_{3}^{-}\right)$(Table 1). At high concentrations of added $\mathrm{HCO}_{3}^{-}\left(8.00-20.00 \mathrm{mmol} \mathrm{L}^{-1}\right.$ ), the algal cells mainly used the added $\mathrm{HCO}_{3}^{-}$in the presence or absence of AZ. Therefore, the more negative the algal $\delta^{13} \mathrm{C}$ values, the more the algal cells used the added $\mathrm{HCO}_{3}^{-}$ regardless of the growth restrictions. In medium lacking AZ,
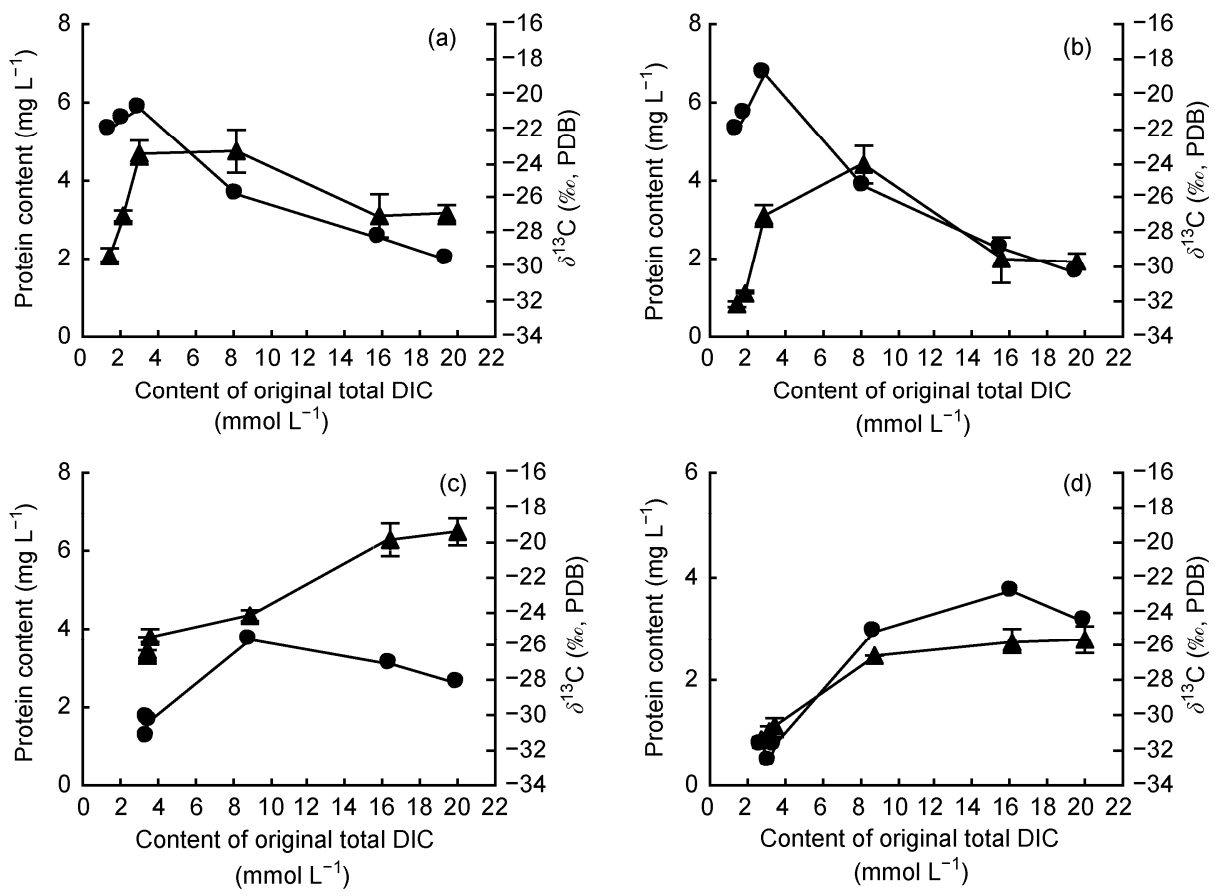

Figure 1 Stable carbon isotope composition $(\bullet)$ and growth $(\boldsymbol{\Delta})$ of Chlamydomonas reinhardtii and Chlorella vulgaris with total dissolved inorganic carbon. (a) C. reinhardtii without AZ; (b) C. vulgaris without AZ; (c) C. reinhardtii + AZ; (d) C. vulgaris + AZ. 
growth of the two algal species was inhibited by the DIC sources because of the high $\mathrm{pH}$ of the culture media. The $\mathrm{HCO}_{3}^{-}$concentration was too high for algal growth in these conditions. The algal cells prioritized uptake of the light ${ }^{12} \mathrm{C}$ isotope, which resulted in a negatively skewed $\delta^{13} \mathrm{C}$ value and higher carbon isotope fractionation. Furthermore, carbon isotope fractionation increased with increasing $\mathrm{pH}$ and $\mathrm{HCO}_{3}^{-}$concentration in the medium. Thus, a linear relationship was observed between the $\delta^{13} \mathrm{C}$ values in algal cells and the total DIC in culture medium lacking $\mathrm{AZ}$ at high added $\mathrm{HCO}_{3}^{-}$concentrations (8.00-20.00 mmol L-1).

Growth of the two algal species was not inhibited by the DIC sources at high added $\mathrm{HCO}_{3}^{-}$concentrations (8.00$20.00 \mathrm{mmol} \mathrm{L}^{-1}$ ) in the presence of AZ because of the moderate $\mathrm{pH}$ of the culture medium. The algal cells produced little carbon isotope fractionation during the growth period because of the unrestricted DIC. Therefore, the $\delta^{13} \mathrm{C}$ values of the algal cells with $\mathrm{AZ}$ were higher than those in medium lacking AZ.

The algal growth rate and cell size in $C$. reinhardtii were higher than those of $C$. vulgaris at 16.00 and $20.00 \mathrm{mmol}$ $\mathrm{L}^{-1}$ added $\mathrm{HCO}_{3}^{-}$. Therefore, the $\delta^{13} \mathrm{C}$ values of $C$. reinhardtii were lower than those of $C$. vulgaris at 16.00 and 20.00 mmol L ${ }^{-1}$ added $\mathrm{HCO}_{3}^{-}$.

\subsection{Dosage effect of acetazolamide on the stable carbon isotope signature}

Low AZ concentrations $\left(0-0.1 \mathrm{mmol} \mathrm{L}^{-1}\right)$ promoted growth of $C$. reinhardtii, whereas high $\mathrm{AZ}$ concentrations (0.5-1 mmol L ${ }^{-1}$ ) slightly inhibited growth. In the concentration range tested, $\mathrm{AZ}$ exhibited no significant effect on the growth of $C$. vulgaris. The effect of AZ on the stable carbon isotope fractionation of $C$. reinhardtii was similar to that of $C$ vulgaris (Figure 2 ). The two algal species showed positively skewed $\delta^{13} \mathrm{C}$ values because of the slight inhibition of CAex activity by $\mathrm{AZ}$ at low concentrations, and negatively skewed $\delta^{13} \mathrm{C}$ values because of the high inhibition of CAex activity by high AZ concentrations. These results indicated AZ has a dose-dependent effect on algal stable carbon isotope fractionation.

\section{Conclusions}

Extracellular carbonic anhydrase can significantly influence stable carbon isotope fractionation of $C$. reinhardtii and $C$. vulgaris under normal growth conditions. The CAex of $C$. reinhardtii and $C$. vulgaris contributes approximately $9 \%$ of the stable carbon isotope fractionation, which was derived from the difference between the smaller fractionation

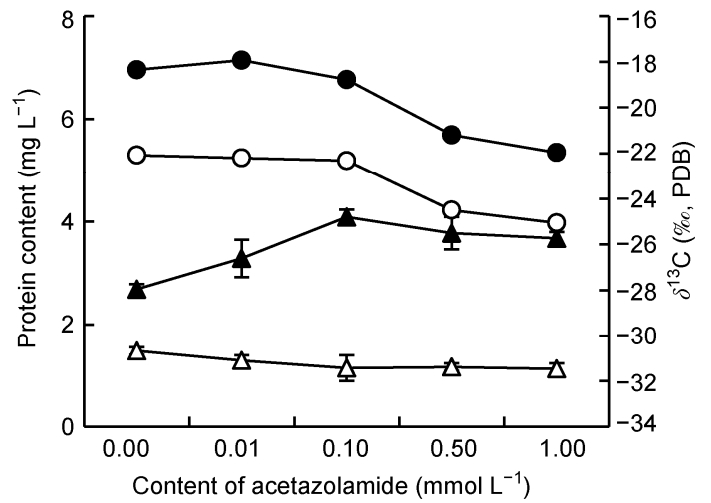

Figure $2 \quad \delta^{13} \mathrm{C}$ values and growth of Chlamydomonas reinhardtii and Chlorella vulgaris at different $\mathrm{AZ}$ concentrations. $\bullet, \delta^{13} \mathrm{C}$ of $C$. reinhardtii; $\circ, \delta^{13} \mathrm{C}$ of $C$. vulgaris; $\boldsymbol{\Delta}$, protein content of $C$. reinhardtii; $\triangle$, protein content of $C$. vulgaris.

from the catalyzed conversion of $\mathrm{CO}_{2}$ to $\mathrm{HCO}_{3}^{-}$and the larger fractionation from the uncatalyzed, slow interconversion. Moreover, CAex had a dose-dependent effect on algal stable carbon isotope fractionation, which could cause a large deviation in the predicted paleoenvironmental $\mathrm{CO}_{2}$ concentration based on the algal carbon isotope composition.

This work was supported by the National Natural Science Foundation of China (40973060 and 31070365).

1 Hollander D J, McKenzie J A. $\mathrm{CO}_{2}$ control on carbon isotope fractionation during aqueous photosynthesis: A paleo- $p \mathrm{CO}_{2}$ barometer. Geology, 1991, 19: 929-932

2 Singer A J, Shemesh A. Climatically linked carbon isotope variation during the past 430000 years in Southern Ocean sediments. Palaeoceanography, 1995, 10: 171-177

3 Werne J P, Hollander D J. Balancing supply and demand: Controls on carbon isotope fractionation in the Cariaco Basin (Venezuela) Younger Dryas to present. Mari Chem, 2004, 92: 275-293

4 Bade D L, Pace M L, Cole J J, et al. Can algal photosynthetic inorganic carbon isotope fractionation be predicted in lakes using existing models? Aquat Sci, 2006, 68: 42-153

5 Mook W G, Bommerson J C, Staverman W H. Carbon isotope fractionation between dissolved bicarbonate and gaseous carbon dioxide. Earth Planet Sci Lett, 1974, 22: 169-176

6 Marlied J F, O'Leary M H. Carbon kinetic isotope effects on the hydration of carbon dioxide and the dehydration of bicarbonate ion. $\mathrm{J}$ Am Chem Soc, 1984, 106: 5054-5057

7 Chen Z, Cheng $\mathrm{H} \mathrm{M}$, Chen X W. Effect of $\mathrm{Cl}^{-}$on photosynthetic bicarbonate uptake in two cyanobacteria Microcystis aeruginosa and Synechocystis PCC6803. Chin Sci Bull, 2009, 54: 1197-1203

8 Burkhardt S, Riebesell U, Zondervan I. Effects of growth rate, $\mathrm{CO}_{2}$ concentration, and cell size on the stable carbon isotope fractionation in marine phytoplankton. Geochim Cosmochim Acta, 1999, 63: 37293741

9 Yu Y X, Liu C Q, Wang F S, et al. Dissolved inorganic carbon and its isotopic differentiation in cascade reservoirs in the Wujiang drainage basin. Chin Sci Bull, 2008, 53: 3371-3378

Open Access This article is distributed under the terms of the Creative Commons Attribution License which permits any use, distribution, and reproduction in any medium, provided the original author(s) and source are credited. 